\title{
PENGEMBANGAN SISTEM PEMBELAJARAN DALAM JARINGAN PADA MATERI TEORI GRAPH
}

\author{
Nira Radita \\ Program Studi Teknik Informatika \\ Sekolah Tinggi Informatika dan Komputer Indonesia (STIKI) Malang \\ niraradita@stiki.ac.id
}

\begin{abstract}
ABSTRAK
Matematika diskrit merupakan mata kuliah matematika dasar yang di dalamnya memuat banyak konsep-konsep dasar matematika. Banyaknya konsep yang harus dipelajari tidak diimbangi dengan alokasi waktu yang disediakan untuk pembelajaran tatap muka. Untuk mengatasi masalah tersebut maka dilakukan pembelajaran yang mengkombinasikan kegiatan pembelajaran tatap muka di dalam kelas dan kegiatan pembelajaran di luar kelas yaitu melalui kegiatan pembelajaran dalam jaringan. Agar pelaksanaan kegiatan pembelajaran sesuai dengan yang diharapkan, maka perlu dikembangkan sistem pembelajarannya. Tujuan penelitian ini adalah menghasilkan sistem pembelajaran dalam jaringan pada mata kuliah matematika diskrit pada materi teori graph. Penelitian ini adalah penelitian pengembangan dengan mengadaptasi dan memodifikasi model 4D (four $D$ model) yang terdiri dari pendefinisian (define), perancangan (design), pengembangan (develop), dan penyebaran (disseminate) oleh Thiagarajan. Penelitian ini dibatasi pada tahap pendefinisian, perancangan dan pengembangan. Tahap pendefinisian terdiri dari 5 langkah pokok, yaitu front-end analysis, learner analysis, concept analysis, task analysis, dan specifying instructional objective. Pada tahap perancangan meliputi constructing criterion-referenced test, media selection, format selection, dan initial design. Tahap pengembangan terdiri dari dua tahap yaitu uji validitas dan uji pengembangan. Hasil penelitian ini berupa sistem pembelajaran dalam jaringan (daring) pada materi teori graph yang dapat diterapkan pada perkuliahan matematika diskrit yang menerapkan pembelajaran blended.
\end{abstract}

Kata kunci: matematika diskrit, pembelajaran dalam jaringan, sistem pembelajaran, teori graph.

\begin{abstract}
Discrete mathematics is the basic mathematical subjects in which includes many of the basic concepts of mathematics. The number of concepts to be learned is not offset by the time allocation of face-to-face learning. To overcome these problems then do blended learning (combination of face to face learning and online learning). In order for the implementation of learning activities as expected, then it needs to design the learning system. The purpose of this research is to produce online learning system in discrete mathematics courses on graph theory material. This is research and development by adapting and modifying the four D model that consists of define, design, develop, and disseminate by Thiagarajan. This study is limited to the definition, design and developstage only. Definition stage consists of five main steps, namely front-end analysis, learner analysis, concept analysis, task analysis, and specifying instructional objective. At the design stage includes constructing criterion-referenced test, media selection, format selection, and initial design. The development phase consists of two stages, validity test and development test. The results of this research is a learning system in the network (online) on the material graph theory that can be applied to discrete mathematics lectures which implement blended learning.
\end{abstract}

Keywords: discrete mathematics, online learning, learning plan, graph theory. 


\section{Nira Radita}

\section{PENDAHULUAN}

Matematika merupakan subjek yang penting dalam kehidupan manusia dan merupakan tubuh dari sains dan teknologi (Acharya, 2017). Pada program studi teknik informatika, terdapat beberapa mata kuliah matematika misalnya kalkulus, matematika diskrit, statistika dan aljabar linear. Masing-masing mata kuliah memiliki peran masing-masing. Sebagai contoh, matematika diskrit merupakan mata kuliah matematika yang di dalamnya memuat teori-teori matematika yang berkaitan dengan bidang teknik informatika. Matematika diskrit merupakan mata kuliah penerapan, mudah, menarik dan memperhatikan kepatutan dan kelayakan (Rosenstein, 1977) serta merupakan pendekatan yang efektif untuk mengilustrasikan dan mengukur lima standar proses pembelajaran matematika menurut NCTM (2000) yang meliputi penyelesaian masalah, komunikasi, penalaran dan pembuktian, representasi dan koneksi (Kenney \& Bezuszka, 1993). Salah satu materi pada matematika diskrit yaitu teori graph. Teori graph merupakan struktur matematika yang banyak diterapkan pada ilmu computer (Gallier, 2008), misalnya pada transaksi konkuren pada basis data terpusat dan untuk pengujian program (Munir, 2001).

Selama ini pembelajaran matematika diskrit dilakukan secara konvensional yaitu dengan pembelajaran tatap muka di dalam kelas. Dengan metode pembelajaran seperti itu, ketika dosen tidak bisa hadir di kampus maka kegiatan pembelajaran tidak dapat dilaksanakan, atau ketika seorang mahasiswa berada di luar kampus maka mahasiswa tersebut tidak dapat mengikuti kegiatan pembelajaran. Sistem informasi pembelajaran online yang tersedia hanya digunakan untuk menyebarkan tugas dan materi pembelajaran sehingga ketika mahasiswa sudah mengikuti kegiatan pembelajaran di dalam kelas maka merasa tidak perlu lagi mengakses sistem tersebut. Sedangkan bagi mahasiswa yang tidak dapat menghadiri pembelajaran tatap muka di dalam kelas bisa memperoleh materi yang diajarkan melalui sistem tersebut, tetapi mahasiswa tidak memiliki kesempatan untuk memperoleh nilai jika pada pertemuan tersebut diberikan kuis atau tugas. Sistem pembelajaran online yang tersedia tidak bermanfaat secara optimal dan hanya berfungsi sebagai repositori materi saja. Selain itu, mata kuliah matematika diskrit memuat konsep dasar matematika yang menuntut tingkat 
kognitif level rendah yaitu mengingat, memahami dan menerapkan (Goksu, 2016). Konsep dasar tersebut dapat dipelajari dalam jaringan oleh mahasiswa dengan cara membaca materi yang tersedia, memperhatikan suatu contoh atau berinteraksi dengan aktivitas pembelajaran tertentu tanpa harus melakukan praktik langsung (Chaeruman, 2017). Agar sistem yang tersedia lebih bermanfaat baik bagi dosen maupun mahasiswa, maka dilakukan pembelajaran dengan moda dalam jaringan (daring). Pembelajaran dalam jaringan dapat digunakan sebagai alternatif ketika kegiatan pembelajaran tidak dapat dilaksanakan sebagaimana mestinya baik melalui aktivitas belajar synchronous misalnya melalui video converence atau live chat, maupun asynchronous melalui kegiatan pembelajaran yang telah dirancang dalam sistem pembelajaran online (Tafqihan, 2011).

Substansi pembelajaran yang disampaikan dalam moda dalam jaringan harus sesuai dengan substansi pembelajaran tatap muka yang meliputi tujuan pembelajaran, konten pada modul, kesesuaian dengan kurikulum dan silabus dan perancangan pembelajaran. Oleh karena itu, perlu dikembangkan suatu sistem pembelajaran yang dapat mengakomodasi kegiatan pembelajaran moda daring tanpa mengurangi substansi pembelajaran tatap muka. Materi yang akan disampaikan dengan moda daring harus sesuai dengan materi yang disampaikan dengan moda tatap muka. Selain itu, media pembelajaran moda daring juga harus bisa memfasilitasi mahasiswa untuk aktif membangun pengetahuan melalui forum diskusi. Dan pada akhirnya, evaluasi pelaksanaan pembelajaran juga dapat diukur dengan assessment yang juga sudah tersedia pada media tersebut.

\section{METODE PENELITIAN}

Penelitian ini merupakan penelitian pengembangan dengan mengadaptasi dan memodifikasi model 4D (four D model) oleh Thiagarajan, dkk. (1974). Model penelitian 4D Thiagarajan yang meliputi tahap pendefinisian (define), perancangan (design), pengembangan (develop), dan penyebaran (disseminate) dibatasi pelaksanaannya pada penelitian ini yaitu hanya pada tahap pendefinisian perancangan dan pengembangan. Tahap pendefinisian dilakukan untuk menetapkan dan mendefinisikan syarat-syarat pembelajaran yang di dalamnya memuat tahap-tahap front-end analysis, learner analysis, concept analysis, task 


\section{Nira Radita}

analysis, dan specifying instructional objective. Tahap perencanaan (design) bertujuan untuk merancang prototype dari media pembelajaran moda daring yang meliputi empat langkah pokok yaitu constructing criterion-referenced test, media selection, format selection, dan initial design. Kegiatan ini merupakan penyajian rancangan awal dari pembelajaran moda daring pada materi graph. Tahap pengembangan bertujuan untuk menghasilkan sistem pembelajaran yang telah direvisi berdasarkan masukan para ahli selanjutnya digunakan dalam tahap uji coba. Tahapan penelitian yang dilakukan digambarkan pada Gambar 1.

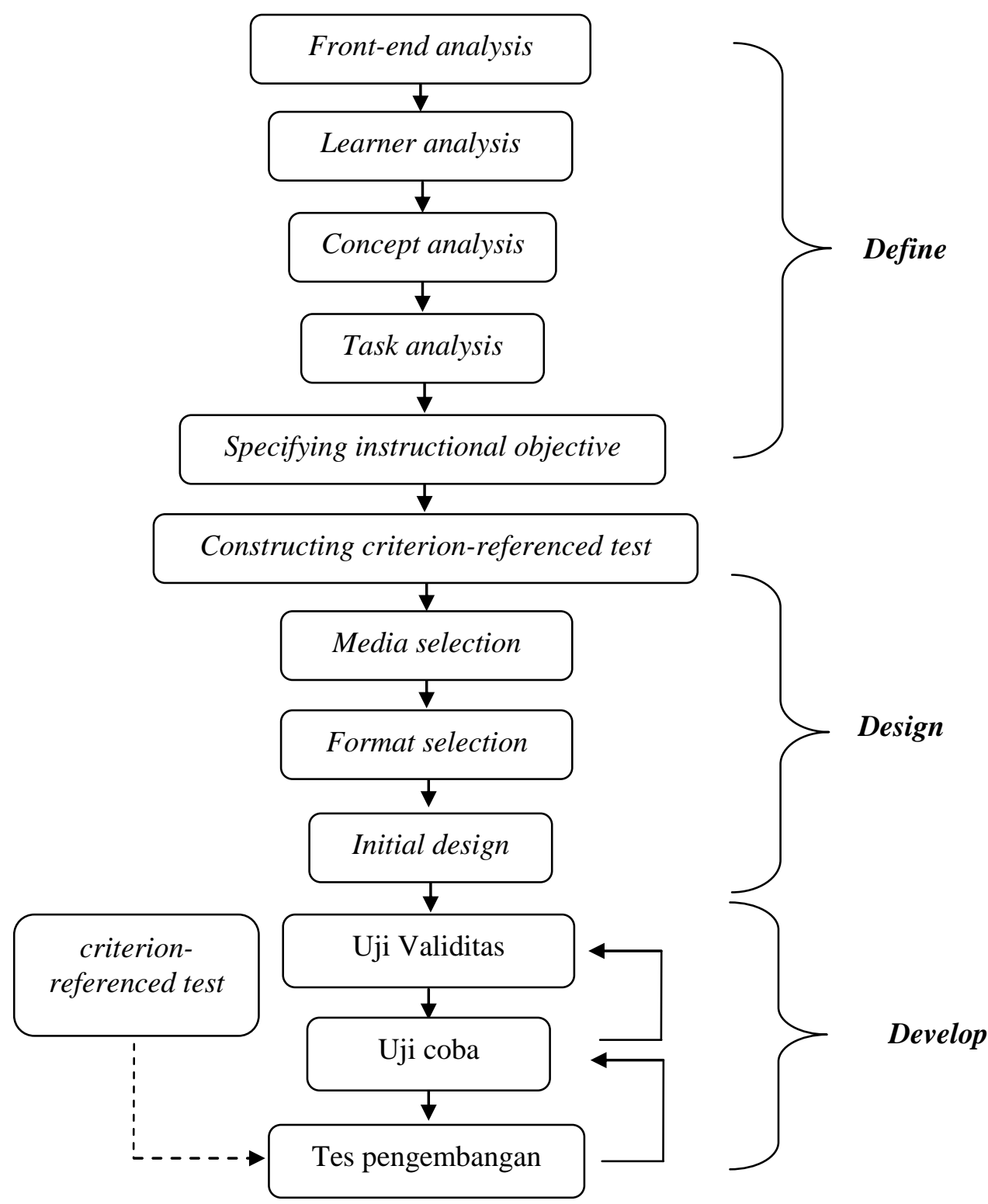

Gambar 1. Diagram Tahapan Penelitian 


\section{HASIL PENELITIAN DAN PEMBAHASAN}

Tahapan pengembangan yang dilakukan dalam penelitian meliputi3 tahapan, yaitu tahap pendefinisian (define), perancangan (design) dan pengembangan (develop).

1. Tahap pendefinisian (define) meliputi 5 langkah pokok sebagai berikut. front-end analysis

Tujuan dilakukannya tahap ini adalah untuk menganalisis permasalahan dasar yang terjadi dalam kegiatan pembelajaran sehingga dapat dikembangkan sistem pembelajaran yang sesuai untuk mengatasi masalah dasar tersebut. Pada tahap ini diperoleh beberapa masalah dasar yang muncul antara lain sebagai berikut:

a. sistem pembelajaran online yang tersedia (ebelajar.stiki.ac.id) belum dimanfaatkan secara optimal, mahasiswa yang sudah mengikuti kegiatan tatap muka di dalam kelas merasa tidak perlu lagi mengunjungi sistem tersebut;

b. materi teori graph terdiri dari banyak konsep-konsep baru yang bisa dipahami dengan belajar mandiri;

c. materi teori graph memiliki koneksi dengan mata kuliah-mata kuliah lain pada program studi teknik informatika;

d. banyak materi yang harus dipelajari pada mata kuliah matematika diskrit sedangkan alokasi waktu tatap muka terbatas.

Dari hasil analisis tersebut, maka kegiatan pembelajaran online diatur sebagai satu-satunya sistem pembelajaran untuk suatu materi pokok tertentu sehingga harus dilakukan oleh setiap mahasiswa tanpa mengandalkan pembelajaran tatap muka. Dalam pembelajaran online disediakan konsep-konsep baru yang menuntut tingkat kognitif level rendah yaitu mengingat, memahami dan menerapkan dimana mahasiswa hanya perlu membaca materi yang disediakan, mendengar penjelasan melalui video pembelajaran, mengamati slide materi tanpa harus melakukan praktik langsung (Chaeruman, 2017). Sedangkan untuk tingkat kognitif level tinggi akan dicapai dengan kegiatan pembelajaran tatap muka. 


\section{Nira Radita}

\section{learner analysis}

Pebelajar adalah mahasiswa STIKI jurusan Teknik Informatika tahun pelajaran 2017/2018 pada mata kuliah matematika diskrit. Dari hasil analisis pebelajar diperoleh data bahwa:

a. pebelajar sudah terbiasa dengan pembelajaran daring pada mata kuliah lain;

b. di STIKI sudah tersedia sistem pembelajaran online yang bisa diakses setiap mahasiswa sesuai dengan mata kuliah yang diambil pada semester yang berkaitan dimana melalui sistem tersebut dapat dilakukan interaksi antara dosen ke mahasiswa, mahasiswa ke dosen dan mahasiswa ke mahasiswa;

c. matematika diskrit merupakan mata kuliah matematika pertama yang ditempuh oleh pebelajar.

Hasil analisis pebelajar tersebut merupakan faktor pendukung dilaksanakannya kuliah dalam jaringan sehingga mahasiswa diharapkan sudah mampu beradaptasi dengan sistem pembelajaran online.

\section{concept analysis}

Analisis konsep bertujuan untuk mengidentifikasi, merinci dan menyusun secara sistematis materi yang sesuai dengan pengetahuan yang sudah pebelajar dapatkan dan pengetahuan yang harus dipahami pada mata kuliah lainnya. Materi yang telah diperoleh mahasiswa yang merupakan materi prasyarat untuk perkuliahan teori graph yaitu materi himpunan dan relasi. Sedangkan mata kuliah yang akan diperoleh mahasiswa pada semester berikutnya yang membutuhkan teori graph sebagai materi prasyarat antara lain basis data, struktur data dan keamanan komputer.Pada setiap materi yang dibahas akan disajikan instruksi kegiatan, forum diskusi, materi yang dilengkapi dengan contoh soal dan diakhiri dengan kuis sebagai sarana penilaian. Materi graph yang dibahas pada pembelajaran ini meliputi:

a. definisi graph,

b. terminologi graph dan

c. representasi graph.

Setelah ditentukan konsep yang akan diajarkan, konsep-konsep tersebut diorganisasikan ke dalam subpokok bahasan dan pokok-pokok materi. Hasil pengorganisasian tersebut dijabarkan pada tabel 1 . 
Tabel 1. Organisasi Materi

\begin{tabular}{|l|l|l|}
\hline Pokok Bahasan & \multicolumn{1}{|c|}{ Subpokok Bahasan } & \multicolumn{1}{|c|}{ Pokok-pokok Materi } \\
\hline Graph & Definisi Graph & Definisi Graph \\
\cline { 2 - 3 } & Terminologi Graph & a. Ketetanggaan \\
& & b. Bersisian \\
& & c. Simpul Terkecil \\
& d. Derajat \\
& e. Lintasan \\
& f. Sirkuit/Siklus \\
& & g. Terhubung \\
\cline { 3 - 3 } & Representasi Graph & h. Subgraph \\
& & a. matriks ketetanggaan \\
& & b. matriks bersisian \\
\hline
\end{tabular}

\section{task analysis}

Analisis tugas pada penelitian ini bertujuan untuk mengukur keberhasilan pembelajaran atas konsep-konsep yang telah disajikan. Indikator ketercapaian pembelajaran diwujudkan dalam bentuk soal yang harus dikerjakan oleh mahasiswa. Beberapa indikator ketercapaian pembelajaran yang dimaksud dalam penelitian ini antara lain:

a. membedakan antara graph dan bukan graph;

b. menentukan derajat masuk dan derajat keluar masing-masing simpul;

c. menentukan simpul terasing, simpul yang bertetangga, sisi yang bersisian;

d. menyatakan graph menggunakan matriks ketetanggaan dan matriks bersisian.

\section{specifying instructional objective}

Sistem pembelajaran ini bertujuan agar mahasiswa dapat menyelesaikan masalah graph melalui beberapa aktifitas yang dirancang dalam pembelajaran moda daring serta mahasiswa dapat menerapkan graph dalam bidang Teknik Informatika. Tercapainya tujuan pembelajaran tersebut dapat dilihat dari nilai kuis yang diperoleh oleh mahasiswa setelah mengikuti seluruh tahapan pembelajaran pada suatu materi pokok. Dari tujuan pengembangan tersebut disusun tujuan pembelajaran sebagai berikut:

a. diberikan definisi graph, mahasiswa dapat membedakan antara graph dan bukan graph;

b. mahasiswa dapat menyebutkan derajat masuk dan derajat keluar dari masing-masing simpul; 
c. mahasiswa dapat menentukan simpul terasing, simpul yang bertetangga dan sisi yang bersisian;

d. mahasiswa dapat merepresentasikan graph melalui matriks.

\section{Tahap Perencanaan (design)}

Tahap ini meliputi empat langkah pokok sebagai berikut. constructing criterion-referenced test

Pada penelitian ini diberikan tiga macam tes yaitu tes awal (pretest), kuis 1dan kuis 2. Pretest disusun untuk mengetahui kemampuan prasyarat mahasiswa sebelum mempelajari materi teori graph. Hasil dari pretest digunakan oleh peneliti untuk menentukan apakah mahasiswa sudah memahami materi prasyarat perkuliahan teori graph atau belum. Soal yang diberikan pada pretest meliputi materi himpunan, relasi dan fungsi.

Kuis 1 diberikan setelah mahasiswa mempelajari definisi graph dan terminologi graph. Hasil kuis 1 menunjukkan pemahaman yang diperoleh oleh mahasiswa setelah menerapkan sistem pembelajaran daring pada materi definisi graph dan terminologi graph. Kuis 2 diberikan setelah mahasiswa menempuh materi representasi graph. Hasil kuis 2 menunjukkan kemampuan mahasiswa dalam merepresentasikan graph ke dalam matriks.

\section{$\underline{\text { media selection }}$}

Media pembelajaran yang digunakan pada pelaksanaan pembelajaran moda dalam jaringan antara lain slide tiap-tiap materi pembelajaran dan video yang memuat masalah sehari-hari yang berkaitan dengan materi teori graph. Slide yang dirancang pada pembelajaran ini antara lain:

a. masalah dasar pada matematika diskrit;

b. definisi graph;

c. terminologi graph;

d. representasi graph.

\section{format selection}

Kegiatan ini bertujuan untuk memilih format yang digunakan mendesain isi dari sistem pembelajaran moda daring pada mata kuliah 
matematika diskrit. Pada bagian pendahuluan memuat judul mata kuliah, dosen pengasuh, salam pembuka, deskripsi mata kuliah, kompetensi, rencana babakan, rencana pelaksanaan, rencana assesment. Pada bagian isi pembelajaran memuat pretest, info awal, materi bacaan, link ke sumber lain, slides, video, tugas, latihan, dan kuis. Pada bagian penutup diberikan kuis.

\section{$\underline{\text { initial design }}$}

Berikut ini adalah rancangan awal media pembelajaran yang dihasilkan.

a. Bagian pendahuluan berisi tentang:

Rancangan bagian pendahuluan ditunjukkan pada gambar 2.

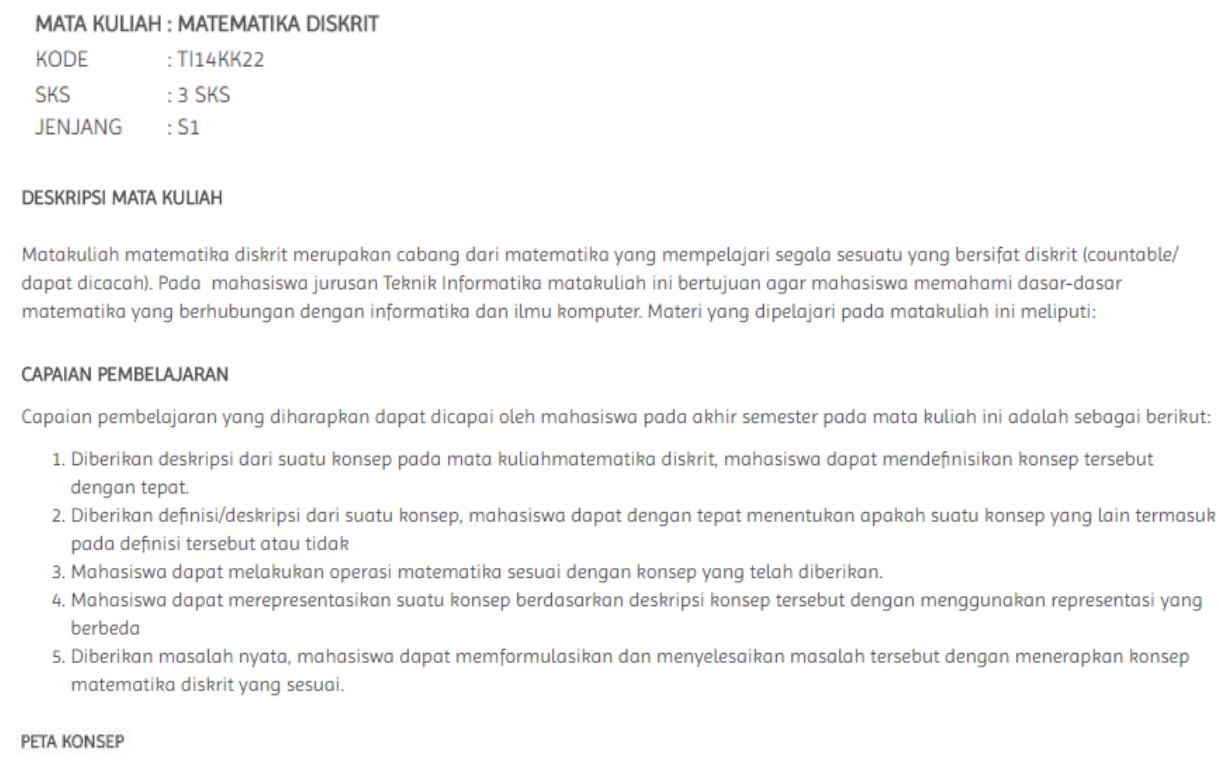

Gambar 2. Desain Bagian Pendahuluan

b. Bagian isi merupakan bentuk perwujudan dari hasil organisasi materi, setting pembelajaran, rencana aktivitas pembelajaran dan alur pembelajaran. Rancangan bagian isi ditunjukkan pada gambar 3 . 
Nira Radita

\section{POKOK BAHASAN: TEORI GRAPH}

Banyak masalah kehidupan sehari-hari yang dapat diabstraksi sebagai masalah yang berkaitan dengan himpunan benda-benda diskrlt dan relasi biner pada benda-benda tersebut.

Perhatikan video berikut. Video ini menyajikan tentang penerapan graph dalam kehidupan sehari-hari.

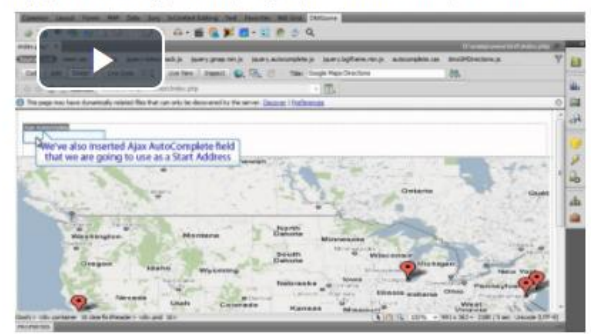

Dalam berbagai masalah yang berkaitan dengan benda-benda diskret dan relasi biner, representasi grafik seringkali merupakan bentuk penyajian yang memudahkan. Hal ini menuntun kita pada pembelajaran tentang teori graf, suatu pembelajaran tentang aplikasi dari Motematiko Dishret. Beribut ini adatoh peneropan graph dolam persoaton matematika diskr

Contoh 1: Stuktur kimia
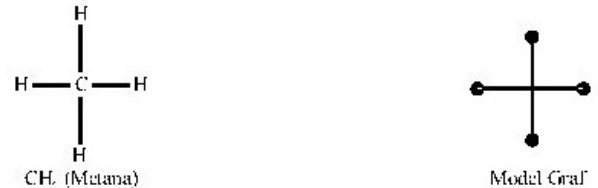

Contoh 2 : jaringan komunikas

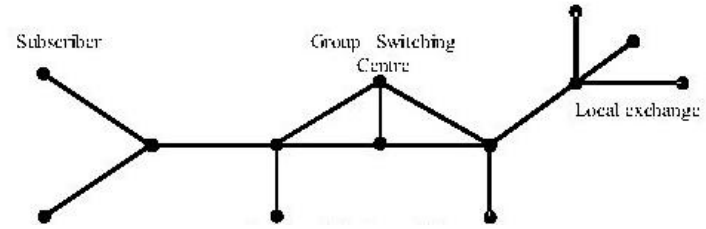

Contoh-contoh di atas merupakan beberapa contoh tentang aplikasi graf dalam sistem model yang nyata. Dalam setiap persoalan, graf memberikan sebugh sruktur model tentang sistem yang kita pelajari, menjeloskan interaksi dan hubungan antara berbagoi komponen

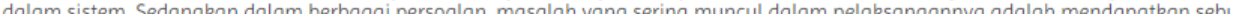
penyusuna yang memenuhi semua permintaan, dan optimal menurut beberapa kriteria seperti harga, pengeluaran atau penampilan. Untuk masalah-masalah dasar yang sering muncul pada matematika diskrit silakan baca pada file berikut

Sirkuit adalah intasan yang berawal dan berakhir pada simpul yang sama disebut sirkuit atau siklus. Ada dua sirkuit yang akan kita bahas, yaitu Sirkuit Euler dan Sirkuit hamilton. Untuk lebih jelasnya, silahkan pelajari slide berikut.

PB. materi sirkuit

Untuk apa kita belajar sikuit Euler? Perhatikan video berikut agar kalian tahu manfaat mempelajari sirkuit Euler

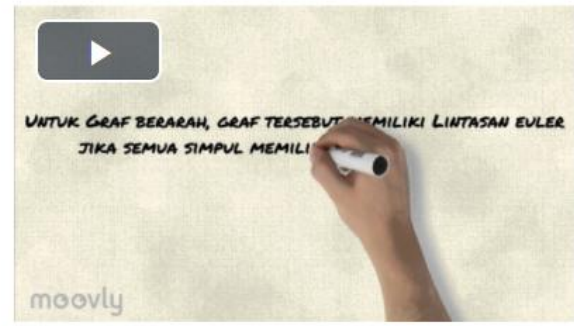

Gambar 3. Desain Bagian Isi

c. Bagian penutup memuat forum diskusi dan kuis. Rancangan bagian penutup ditunjukkan pada gambar 4. 
Jika mengalami kesultan dalam memahami materi, silakan tuliskan masalah yang ditemui pada forum berikut, setiap mahasiswa berhak menuliskan satu masalah (masalah bisa berupa kalimat yang tidak bisa dimengerti atau materi yang membutuhkan penjelasan lebih lanjut). Diharapkan agar membaca masalah yang sudah dituliskan mahasiswa sebelumnya agar tidak mengulang masalah yang same Selain menuliskan masalah. itka merasa mampu dan memahami mosalah yang dituls hen oleh mahasiswa lain, maka mahasiswa diijinkan untuk menjawabnya.

\section{Gambar 4. Desain Bagian Penutup}

3. Tahap Pengembangan

Tujuan tahap ini adalah menghasilkan sistem pembelajaran daring Matematika Diskrit yang telah direvisi berdasarkan masukan para ahli, selanjutnya digunakan dalam tahap uji coba. Pada tahap ini terdapat dua kegiatan yang dilakukan yaitu uji validitas dan uji pengembangan.

Validator yang berperan pada uji validitas adalah dosen matematika STIKI Malang yang tidak terlibat dalam penelitian. Validator memberikan penilaian terhadap sistem pembelajaran menurut beberapa indikator yang telah disusun oleh peneliti misalnya tentang:

a. kejelasan tujuan, petunjuk dan aktivitas yang harus dilakukan oleh mahasiswa;

b. penggunaan kalimat, bahasa, tanda atau simbol dan warna yang dapat dipahami oleh mahasiswa;

c. manfaat yang mungkin dapat diperoleh dengan perkuliahan menggunakan sistem pembelajaran daring.

Hasil uji validitas diperoleh skor 3,58 yang berarti bahwa sistem pembelajaran daring yang dirancang terbukti valid.

Uji pengembangan dilakukan terhadap 25 mahasiswa STIKI yang sedang menempuh mata kuliah matematika diskrit. Rata-rata skor yang diperoleh oleh 25 mahasiswa tersebut dijelaskan pada tabel 2.

Tabel 2. Nilai Kuis pada Tahap Uji Coba

\begin{tabular}{|l|l|}
\hline \multicolumn{1}{|c|}{ Jenis Tes } & \multicolumn{1}{c|}{ Rata-rata skor } \\
\hline Pretest & 74 \\
\hline Kuis 1 & 85,2 \\
\hline Kuis 2 & 77,6 \\
\hline
\end{tabular}

Hasil pretest menunjukkan bahwa mahasiswa sudah memiliki pengetahuan awal sebagai persyaratan untuk melaksanakan perkuliahan materi teori graph. Hasil kuis 1 menunjukkan bahwa mahasiswa telah memahami materi definisi 


\section{Nira Radita}

graph dan terminologi graph. Kuis 2 menunjukkan bahwa mahasiswa telah memahami materi representasi graph.

Dari hasil uji validitas sistem pembelajaran dan hasil uji pengembangan yang dilakukan terhadap 25 mahasiswa, maka disimpulkan bahwa sistem pembelajaran daring pada materi teori graph valid dan dapat digunakan. Dengan kata lain, sistem pembelajaran yang dikembangkan dapat digunakan untuk mencapai tujuan pembelajaran yang telah ditetapkan.

\section{SIMPULAN}

Pengembangan system pembelajaran matematika diskrit dengan moda dalam jaringan dilakukan melalui tahap perencanaan, perancangan dan pengembangan. Dari hasil pengembangan diperoleh simpulan berikut.

1. Tahap pendefinisian dilakukan melalui 5 tahap yaitu: a) tahap front-end analysis yang menghasilkan latar belakang masalah yang diperlukannya pengembangan rancangan pembelajaran, b) tahap learner analysis menghasilkan latar belakang kondisi mahasiswa, c) tahapconcept analysis menghasilkan gambaran materi yang akan diajarkan, d) tahap task analysis menghasilkan rancangan tugas yang akan diberikan kepada mahasiswa, dan e) tahap specifying instructional objective menghasilkan rumusan tujuan pembelajaran.

2. Tahap perancangan meliputi a) tahap constructing criterion-referenced test menghasilkan butir-butir soal yang akan diberikan untuk mengukur keberhasilan pelaksanaan pembelajaran, b) tahap media selection menghasilkan rancangan media pembelajaran yang akan diterapkan, c) tahap format selection menghasilkan rancangan format pembelajaran daring, dan d) tahap initial design menghasilkan rancangan pembelajaran daring.

3. Tahap pengembangan meliputi dua kegiatan yaitu validitas ahli dan uji pengembangan. Hasil uji validitas menunjukkan bahwa sistem yang dirancang telah valid dan hasil uji pengembangan menunjukkan bahwa sistem pembelajaran dapat digunakan dalam kegiatan perkuliahan dalam rangka menciptakan pengalaman belajar untuk mencapai tujuan pembelajaran yang telah ditetapkan. 


\section{DAFTAR PUSTAKA}

Acharya, B. R. 2017. Factors Affecting Difficulties in Learning Mathematics by Mathematics Learners. International Journal of Elementary Education, 815.

Chaeruman, U. A. 2017. PEDATI - Model Desain Sistem Pembelajaran Blended. Jakarta: Kemenristekdikti.

Gallier, J. 2008. Discrete Mathematics for Computer science Some Notes. Philadelphia.

Goksu, I. 2016. The Evaluation of the Cognitive Learning Process of the Renewed Bloom Taxonomy Using a Web Based Expert System. TOJET: The Turkish Online Journal of Educational Technology - October 2016, volume 15 issue $4,135-151$.

Kenney, M. J., \& Bezuszka, S. J. 1993. Implementing the discrete mathematics standards: Focusing on recursion. Mathematics Teacher, 86(8), 676-680.

Munir, Rinaldi. 2001. Buku Teks Ilmu Komputer Matematika Diskrit. Bandung: Informatika.

National Council of Teachers of Mathematics. (2000). Principles and Standards for SchoolMathematics. Reston, VA: Author.

Rosenstein, J. G. 1997. Discrete mathematics in the schools: An opportunity to revitalizeschool mathematics. In J. G. Rosenstein, D. Franzbalu \& F. Roberts (Eds.), DIMACS Seriesin Discrete Mathematics and Theoritical Computer Science: Discrete Mathematics in theSchools (Vol. 36, pp. xxiiixxx): American Mathematical Society and National Council ofTeachers of Mathematics.

Tafqihan, Z. 2011. Karakteristik dan Pemilihan Media Pembelajaran dalam ELearning. Jurnal Cendekia Volume 2 Nomor 9 tahun 2011, hal: 141-154, ISSN: 2477-796X.

Thiagarajan, et al. 1974. Instructional Development for Training Teachers of Exceptional Children. A Sourse Book. Bloomington: Central for Innovation on Teaching The Handicapped 